\title{
An Integrated Cloud Computing Solution for Romanian Public-Sector Entities: ICIPRO Project
}

\author{
Mihail DUMITRACHE*, Ionuţ-Eugen SANDU, Dragoș-Cătălin BARBU \\ National Institute for Research and Development in Informatics - ICI \\ 8-10, Maresal Al. Averescu Avenue, Bucharest, 011455, Romania \\ mihaildu@rotld.ro (*Corresponding author); ionut@rotld.ro
}

\begin{abstract}
Cloud Computing is a new step in the development of the Internet and enables users to migrate their data, emails, applications, and all new workload demands to virtual systems that can be accessed at any time and from any place, provided there is a permanent connection to the Internet.The first part of the paper reviews basic Cloud Computing concepts, implementation models (Private Cloud, Community Cloud, Public Cloud, Hybrid Cloud), service models (SaaS), Platform as a Service (PaaS), Infrastructure as Service (IaaS)), while the second part sets forth an integrated Cloud Computing solution for Romanian public institutions through the ICIPRO project. The implementation of Cloud's technical solution proved to be successful being a first initiative on Cloud Computing designed for Romanian public sector entities.
\end{abstract}

Keywords: Cloud Computing, IaaS, Infrastructure as a Service, PaaS, Platform as a Service, SaaS, Software as a Service, Virtualization, Hyper-V, Self-Service.

\section{Introduction}

According to a simplified definition, the term "Cloud Computing" refers to the storage, processing and use of data on remote systems accessed via the Internet. This means that users can make use of almost unlimited computing power on demand, they do not need to make major capital investments to meet their requirements, and they can access their data from anywhere via an Internet connection.

Cloud Computing has the potential to reduce users' IT costs and to foster the development of a large number of new services. By using Cloud Computing, even the smallest businesses can target larger markets, while governments can increase the attractiveness and efficiency of their services, while keeping their spending under control.

While the World Wide Web puts information within everyone's reach, anywhere in the world, Cloud Computing brings computing power to everyone, anywhere in the world. Like the Web, Cloud Computing is an innovative technology that emerged some time ago and continues to grow.

Cloud Computing is a new phase of industrialization (standardization, expansion, generalized availability) of supplying computing power as a public utility ("utility computing") comparable to the industrialization of power supply from power plants [1].

A fundamental concept of Cloud Computing is that, through this model, information technology is made available to users in the form of services (as by analogy, communications technology is made available to users in the form of voice / data services) used in the form of periodic subscriptions (just as telephone services are used in the form of a monthly subscription).

The end of the first decade of the $21^{\text {st }}$ century has been described as a "historical turning point" in the development of e-government services and the "coming of age" [2]. These statements, contained in the 2009 eGovernment Working Paper of the European Commission sub-group, are confirmed by the increase in policy measures in this area and changes in the availability and use of information and communication (ICT) in providing public services. When launching the 2011-2015 Electronic Governance Action Plan for Europe [3], Neelie Kroes, Vice President of the Digital Agenda in Europe, underlined the aim of "helping public authorities to use ICT to deliver better service at lower cost, to make life easier and better for citizens and business".

This article presents an integrated Cloud Computing solution for public institutions in Romania, featuring Cloud Computing concepts, models, services and platforms.

The article describes a first initiative on Cloud Computing for public administration in Romania, which leads to avoiding oversized infrastructure purchases. 
Section 2 shows the main cloud models, section 3 presents cloud computing services, while section 4 deals with the requirements needed for implementing national cloud computing as an integrated solution. Further on, the paper presents the ICIPRO Project and section 6 proposes a general architecture for implementing hardware and software infrastructure. The article ends with several discussions and concluding comments presented in section 7 and 8 respectively.

\section{Cloud Models}

In terms of Cloud models, four main use patterns (Private, Public, Hybrid, Community) are identified. Cloud models used in organizations are in most cases Private or Hybrid, while service providers use the Public and Hybrid models. Based on good practice and recommendations from standardization bodies, Cloud models are defined as:

Private Cloud: The IT infrastructure is used by a single multi-consumer organization and can be managed by the organization itself or outsourced to a third party. In case of a Private Cloud, unlike a traditional Data Center, the resources available are optimized. There are many organizations that have implemented their own private Cloud systems such as IBM, HP, Microsoft, etc.

Public Cloud: The IT infrastructure is available to the public or to a part of the public based on certain criteria, or on an industrial segment or area of interest. Within this model, IT infrastructure is owned and managed by a service provider (commercial, governmental, academic, or mixed). Services can be accessed via the Internet and data protection is ensured by the service provider. Examples of Public Cloud services: Windows Azure Platform from Microsoft, AWS from Amazon, AppEngine and Gmail from Google etc.

Hybrid Cloud: The IT infrastructure involves one or more Public or Private Cloud components regarded as a unit using the same technology.

Community Cloud: The IT infrastructure is shared by several organizations in order to provide services to a particular community, which shares the same functional requirements. Within this model the IT infrastructure is owned and operated by one or more organizations from the community, a third party or a combination of them, and may exist physically inside or outside the organization.

\section{Cloud Computing Services}

According to user requirements, there are several Cloud Computing solutions available on the market. These are defined by NIST (National Institute of Standards and Technology) [4] in three main categories or "service models". These models are usually applied to private, public and institutional Cloud.

IaaS (Infrastructure as aService): the first model that complies with NIST Cloud Computing characteristics. In this model a supplier (service provider) rents IT infrastructure, i.e. distant virtual machines that can replace the companies' local IT infrastructure. IaaS includes the entire stack of infrastructure resources providing Automation all the way to advanced virtualization and also providing facilities such as cooling solutions, electric power, etc. for the hardware platforms hosted. The provider of such services is responsible for the management of possible hardware failures.

Examples of IaaS: Amazon Web Service (AWS), Google Compute Engine (GCE), Rackspace Cloud, IBM Open SmartCloud Enterprise, HP Enterprise Converged Infrastructure.

PaaS (Platform as aService): the provider supports and offers pre-configured components including programming languages, application servers and databases for web application developers. PaaS sits between IaaS and SaaS, without being a finished product that can be accessed directly by the end users, but adds - in relation to the IaaS - an extra level of integration with the application development frameworks, middle-ware capabilities and functions, such as databases, stacks of queries.

Examples of PaaS: Engine Yard, Red Hat OpenShift, Google App Engine, Heroku, AppFog, Windows Azure Cloud Services, Amazon Web Services, AWS, Caspio.

SaaS (Software as a Service): the most common form of Cloud for the common user - the service 
provider offers "on-demand" applications to the end users. These applications, usually paid by subscription, are hosted and managed by the service provider and replace traditional applications installed by users on their equipment. Such services are largely intended for webbased desktop applications such as e-mail, word processing, spreadsheet, presentations, calendars, diaries, etc.

Examples of SaaS: Microsoft Office 365, Google Gmail, Google Docs, Zoho Office, Salesforce, Citrix GoToMeeting, Cisco WebEx.

Referring to the three models presented above (IaaS, PaaS, SaaS) one should bear in mind that there are important trade-offs for each of them, regarding the integrated features and complexity on one side - and the extensibility and security on the other side. Trade-offs among the three Cloud models' deployment include:

- SaaS provides the most integrated functionality with the slightest possibility of extensibility and relatively high level of security (the provider bears a significant share of responsibility for security);

- PaaS allows developers to build their own applications in the upper area of the platform. Therefore, it tends to be more extensible than SaaS. This trade-off extends to security elements, but, based specifically on its flexibility, offers the possibility of integrating an additional security layer;

- IaaS provides the highest level of extensibility. This means that, in general, security capabilities and functionalities do not go beyond protecting the infrastructure itself. This model assumes that the operating systems, applications and content will be managed and secured by the client [5].

\section{Requirements for Implementing National Cloud Computing as an Integrated Solution}

Implementing Cloud Computing as an integrated solution, on national level involves the following:

1. Data center consolidation: Provides IT resources, storage and processing and communication that will enable the ministries, agencies and other central or local authorities to migrate computing hardware found in the form of local data centres, or individual computers, on a single central platform, available in a high-availability system based on best practices, thereby reducing costs withadministration of the local, own IT infrastructure, specific to each institution.

2. Continuity of service in the aftermath of a disaster (Business Continuity):

- Builds a platform that allows saving data belonging to any local or public institution in Romania.

- Stores images of applications and databases onto a central storage space, allowing for rapid recovery in case of an error occurred within the primary productive system.

- Backup and recovery mechanisms enable planning and execution through the network, allowing users to optimally use your network resources.

3. A Cloud Computing Platform that will ensure:

- Improving data centre capabilities both in terms of functionality offered by the building, mechanical and electrical mechanisms made available for operational support.

- Improving network capacity in order to provide effective and centralized support for information systems.

4. Cloud Computing Services that will define the basics of Cloud Computing services development:

- Provide adequate services to enable different public institutions to move their core business operations to Cloud Computing platform, or to develop new electronic services. These services will provide IT resources (Processors, Storage Space, Communication Capabilities) as well as specialized software platforms. These services as a whole will be services of the following types: IaaS (Infrastructure as a Service) and PaaS (Platform as a service);

- Ensure a national interoperability platform, providing data integration services and shared services.

- Develop e-government capabilities by implementing specific electronic services. 
5. Training and development by providing:

- Training the staff that uses and manages the Cloud Computing integrated solution.

- Online training for the entire Romanian IT\&C community on Cloud Computing services of the Romanian Government.

- Developing expertise in order to implement national electronic services by providing all the necessary information and an operational framework that makes it possible to define, develop and implement the above mentioned services.

\section{ICIPRO Project}

Such a solution has been implemented and tested at the National Institute for Research and Development in Informatics - (ICI Bucharest) through the project ICIPRO (CLOUD INFRASTRUCTURE for PUBLIC INSTITUTIONS in ROMANIA), a Cloud platform designed for Romanian publicsector entities covering the following services: Infrastructure as a Service(IaaS), representing virtual servers, data storage, virtualized cloud resources with access to the self-service type interface; Catalogue of applications/services in the cloud which presumes their existence and integration into a marketplace-type platform (catalogue) and contracting a pack of applications and the corresponding subscriptions in order to use them; Virtual library service through which public institutions may gain access to electronic archiving services and have the possibility to display them through a portal with public access to electronic documents; Open data service through which public institutions contributes to increasing transparency in public administration, having the opportunity to publish in a standardized way information of public interest, on its own initiative, or in response to public requests [6].

ICIPRO is the first consistent initiative related to Cloud Computing in public administration in Romania and should lead to avoiding waste of money in acquiring oversized infrastructures for services that in reality, enjoy only limited success. Through the flexibility the Cloud model proposes the resources allotted to any service (application) can trace transparently the resource requirements for that service. In this respect, ICIPRO platform can be a good indicator, with an overall perspective, of the level of public services implemented on the desired technical platform. Through monitoring capabilities, ICIPRO platform can look objectively how often a service is used for a public service.

ICIPRO combines the benefits of a public cloud (on-demand, self-service, scalability) with those usually associated with on-premise environments (governance, predictability, control) and is presented primarily as a IaaS service (infrastructure - Infrastructure as a Service).

Components of the technical solution come from large scale manufacturers, with recognized reputation, able to support consistent implementation of these components in Romania, as well as their maintenance.

The main sub-system that forms the foundation for Cloud operation is represented by the management sub-system without which virtual machines created by tenants cannot run properly - it is the core of the Cloud. In the Figure 1, we briefly present these services that work together to serve the tenants' needs to manage their own resources.

From a logical point of view, these servers are connected to each other through a local management network totally isolated from tenants' networks. Cloud infrastructure management is secured only from a specific network area, based on a complete Microsoft-based identity system: Active Directory Domain Services, Active Directory Certificate Services, including Active Directory Federation Services for integration and authentication of services that are connected to the exterior (the self-service portal). This identity system is also used by virtualization provisioning and management servers that work with configuration management servers to maintain the uniformity of existing operating systems as well as easy management of the entire infrastructure.

Operation of these services is carefully monitored by the monitoring service, which presents in real time the state of the whole system and warns when problems arise. Also, automated backup services to quickly restore data in case of data loss/corruption. 


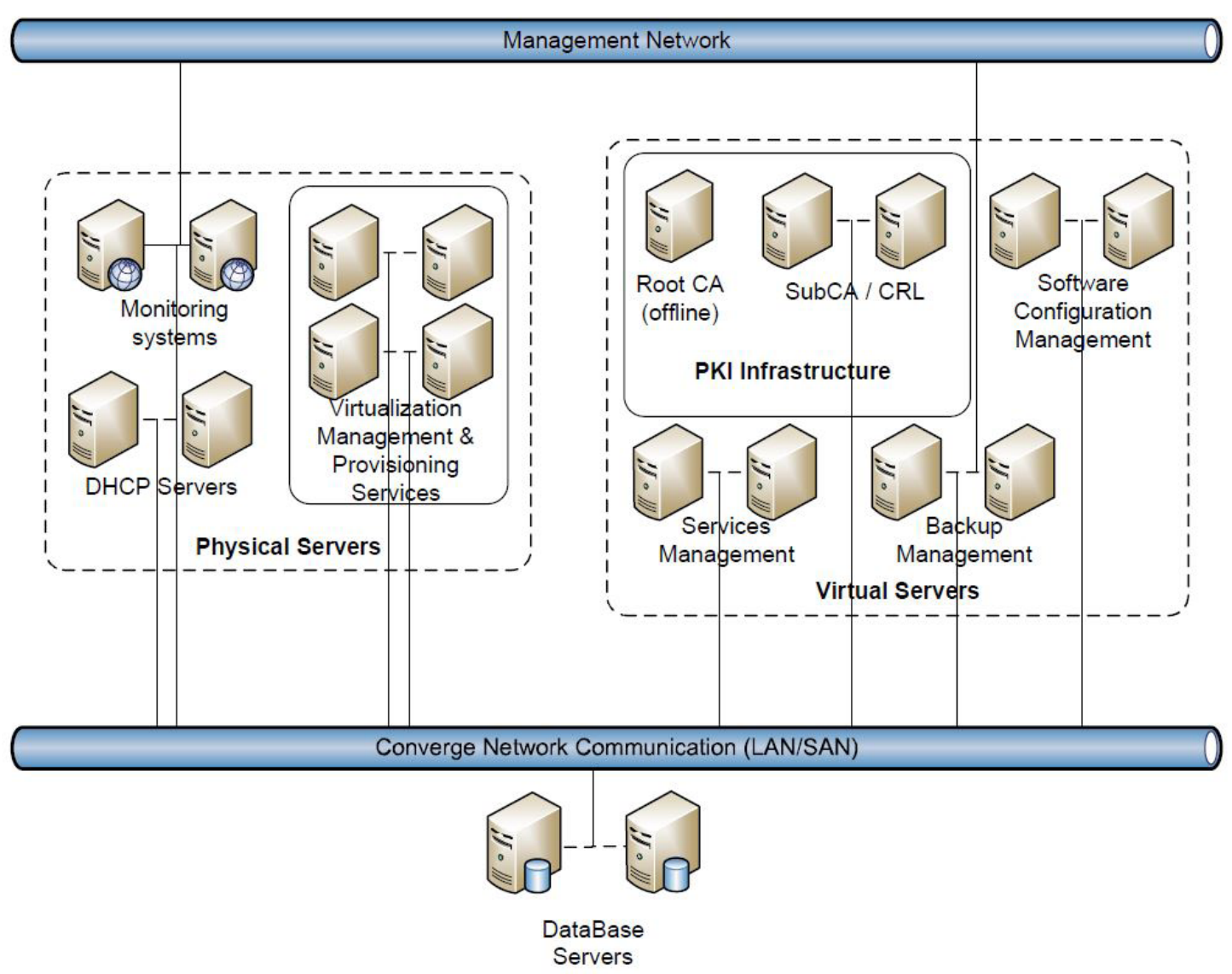

Figure 1. ICIPRO general architecture

All irrelevant information is kept in a clustered database that obviously has Microsoft technology behind it, in order to have a high level of compatibility with all existing services.

From the point of view of network connections between end-devices, a simple, flexible and secure implementation was desired, based on the latest technologies that are able to provide a high level of performance; that is why we opted for a convergent communication infrastructure.

\section{General Architecture}

The general architecture took note of good practices in the field of IT, providing high availability of all critical services by eliminating the Single Point of Failure "(SPoF) and ensuring an optimal level of security on all levels (Figure 1).

\subsection{ImplementingHardware Infrastructure}

The hardware infrastructure is provided by:

- Servers: NEC (Nippon Electric Corporation) - traditional manufacturer of servers with a high level of quality and performance; it is notable that NEC is firmly committed, through public statements, in promoting the Cloud Computing model in Romania.

- Systems of data storage: HP - a manufacturer with a wide range of advanced equipment in storage portfolio, with a consistent presence in Romania.

- Communication infrastructure: Cisco - world leader in communications infrastructure.

- Backup tape drive: IBM.

\subsection{Implementing Software Infrastructure}

The infrastructure is provided by Microsoft software (operating systems, virtualization, provisioning and management system) - the world's largest software company in the world, one of the promoters of the Cloud Computing model worldwide, with products and technologies that have reached highest level presently, the Hypervisor (worldwide: Microsoft Hyper-V Server R2; Operating systems: Microsoft 
Windows Server 2012 R2; System provisioning and infrastructure management: Microsoft System Center R2 2012, complemented by Windows Azure Pack; Users management platform: Microsoft Active Directory; Database management system of Microsoft SQL Server database: 2014 Enterprise Edition).

Infrastructure services are based on the Microsoft virtualization platform Hyper-V R2, 2012 a virtualization platform recognized among industry leaders. In the 2012 R2 edition Hyper-V brings a series of remarkable improvements, including support for large virtual machines (up to 64 virtual processors, 1TB RAM), for an increased number of virtual machines, and also improvements related to resource monitoring, virtual machine and storage space migration etc. Within the ICIPRO project the physical servers were divided according to the requirements of safety and data offered by manufacturers in 4 categories (Fabrics):

- Management - 20 nodes: here lie the servers that manage the entire IaaS infrastructure (ADDS, ADCS, SCVMM, Azure, SQL, Backup, Gateway etc.)

- Fabric A - 62 processing nodes (type 1 servers - NEC Express5800/E120e-M) dedicated virtual machine tenants, totalling a processing power that includes 1984 virtual processors, 7932 GB RAM and $70140 \mathrm{~Gb}$ storage space

- Fabric B - 62 processing nodes (type 1 servers - NEC Express5800/E120e-M) dedicated virtual machine tenants, totalling a processing power that includes 1984 virtual processors, 7932 GB RAM and $70140 \mathrm{~Gb}$ storage space

- Fabric $\mathrm{C}-4$ processing nodes (type 2 servers - NEC Express5800/A2040b) - dedicated virtual machine tenants totalling a processing power that includes 384 virtual processors, $1496 \mathrm{~GB}$ RAM and $21560 \mathrm{~Gb}$ storage space

\section{Discussions}

Through the self-service Portal included within the infrastructure services, entitled users (representatives of public institutions) can provide and manage infrastructure services made available by ICIPRO. Specifically, through this portal they will be able to define virtual machines, manage their parameters, will be able to define and manage complex services consisting of multiple virtual machines, and more. In order to create virtual machines, there are various hardware profiles and templates with various operation systems, such as Linux (Centos, Ubuntu) or Windows 2012R2. Tenants can also define different types of virtual networks having dedicated external IP addresses, can create VPN tunnels with onpremises resources; all these benefiting from a level of isolation and security offered by protocols such as NVGRE.

Currently the system has several beneficiaries, apart from ICI-Bucharest - the owner - that has moved 70 percent of its IT infrastructure to the Cloud.

The Cloud platform provides services to 29 entities, while for other entities the platform is in the process of «establishing the specific usage procedures». Totally, there are 29 subscribed public institutions as follows:

- $\quad$ Ministries and ministerial agencies: 13

- Universities/Colleges: 6

- Libraries: 4

- $\quad$ Institutes/Research Institutions: 4

- $\quad$ City halls: 2

In the implementation of the project some problems were identified, among which the following are worth mentioning:

1. Following the exploitation by the tenants of the cloud infrastructure, a difference was found between the information held by SCMSM and the non-Microsoft switches in relation to the number and names of the networks created by the tenants. The cause of the problem increased, namely SCVMM allowed creation of networks that had a "blank" character in their names, while Linuxbased OS switches did not allow these characters.

Corrective measures - it was forbidden to create networks that contained blank characters and configurations of the two entities (Microsoft and the networking manufacturer) were manually synchronized. 
2. Performance problems when tenants access resources. The source of this problem was again located at the intersection of Microsoft technologies and the network equipment manufacturer technologies.

Corrective measures - tuning both SCVMM and third-party switches as a result of collaboration between the specialists of both technologies.

All problems have been corrected and eliminated, and the system is currently working according to the projected parameters.

\section{Conclusions}

ICIPRO project is made in the spirit of promoting e-Government through the use of tools and systems available information and communications technologies (ICT) in order to ensure the prerequisites for offering better public services for citizens and businesses. The general objective of the project is modernisation, development and optimisation of public services offered to the citizens via a Cloud Computing infrastructure that optimises acquisition and usage of ITC at public institutions level, improve the transparency of public institutions activities and facilitate the interoperability between public electronic services.

Cloud Computing Services will become the first option for public institutions, thus ensuring a more efficient use of ICT resources, a significant reduction in costs and a significant increase in the services offered to the citizens. Benefits for users can be expressed succinctly by an easy access, regardless of location and time, at the information they need in an efficient and transparent manner through the web portal created within the project, reducing the actual costs, improving operational management through a better allocation of resources needed to solve the problems and necessities of public institutions.

The solution allows hosting the computing systems that support public institutions activities, as end-users, the objective being to provide high quality electronic services to citizens.

The economic impact of Cloud Computing will not achieve its full potential unless the technology is adopted both by the public authorities, which hold a major purchaser position to promote the development and adoption of Cloud Computing, and small and medium-sized enterprises (SMEs).

Considering that the ICIPRO project has achieved its objectives in a very short time and that the resources supplied have been used to their full potential, ICI Bucharest intends to extend this project by increasing the storage capacity, processing and development of software solutions necessary for the public institutions in Romania, as well as research and development projects within this research institute.

\section{REFERENCES}

1. Comisia Europeană, Valorificarea cloud computing-ului in Europa, <http://eurlex.europa.eu/LexUriServ/LexUriServ. do?uri=COM:2012:0529:FIN:RO:PDF>.

2. Visions and priorities for eGovernment in Europe: Orientations for a post 2010 eGovernment Action Plan, European Commission eGovernment Sub-group, Working Paper (20 March 2009).

3. The European eGovernment Action Plan 2011-2015: Harnessing ICT to promote smart, sustainable \& innovative Government, European Commission COM(2010)743 (15 December 2010).

4. National Institute of Standards and Technology, <http://www.nist.gov/>.

5. GHID Securitatea în Cloud - Asociaţia Naţională pentru Securitatea Sistemelor Informatice, <http://www.cert-ro.eu/ files/doc/775 201310300910570117644 00_X.pdf $>$.

6. Dumitrache, M. (2015). Servicii publice electronice oferite instituţiilor publice prin proiectul ICIPRO (Infrastructură de tip Cloud pentru Instituţiile Publice din România), Revista Română de Informatică şi Automatică, ISSN: 1220 - 1758, 25(4), Bucharest, 27-32. 